\title{
Preparation of iridium and platinum films by MOCVD and their properties
}

\author{
T. GOTO, R. VARGAS and T. HIRAI
}

Institute for Material Research, Tohoku University, 2-1-1 Katahira Aoba-ku, Sendai 980, Japan

\begin{abstract}
Noble metals (Ir, Pt) films were prepared by MOCVD using metal-acetylacetonate precursors. The effects of deposition conditions on deposition rates, composition and microstructure were studied, and the optimum conditions were determined. A small amount of oxygen addition to the source gas was effective to prepare high-purity films. Epitaxially grown films were obtained on several kinds of single crystalline substrates. Black-colored powdery films containing impurity carbon were prepared without oxygen addition. These black films consists of fine particles about several nanometer in size. Ir films prepared without oxygen addition showed superior electrical and catalytic properties as an electrode for zirconia solid electrolytes particularly below $600^{\circ} \mathrm{C}$.
\end{abstract}

\section{INTRODUCTION}

Noble metals, such as Ir and $\mathrm{Pt}$, are promising for protective coatings for high temperature usage because of their high melting point and superior oxidation resistance, in which pore- and microcrackfree films should be prepared [1-3]. These materials also have high electrical conductivity which enables them as electrodes. For microelectronic applications, epitaxially grown electrode films on single crystalline substrates (such as $\mathrm{Si}$ and sapphire) are demanded [4,5]. For the application to solid state electrolytes such as solid fuel cells and gas sensors, in contrast, porous and catalytic electrodes are needed. Therefore, the appropriate morphology for these films should be controlled depending on their applications.

Many kinds of methods including plasma-arc deposition [7], sputtering [8], laser-ablation [9], electron-beam gun deposition [10] and chemical vapor deposition [11] have been employed to prepare these noble metal films. Since films can be prepared under relatively mild conditions (i.e. low deposition temperature, near atmospheric pressures, etc.) and their morphology could be controlled by changing deposition conditions, MOCVD might be advantageous for above-mentioned applications. So far amorphous and poly-crystalline noble metal films have been prepared by MOCVD [3,5], however, no specific preferred orientation nor epitaxial growth have been reported.

In this paper, we report that impurity carbon has significant effect on the morphology of the films, and epitaxially grown films can be obtained by eliminating the impurity carbon. We also found that Ir films containing impurity carbon have excellent electrical and catalytic properties as an electrode for solid electrolytes. 


\section{EXPERIMENTAL}

A schematic diagram of horizontal hot-wall type CVD apparatus was depicted in Fig.1. Ir- and Ptacetylacetonate, $\left(\mathrm{CH}_{3} \mathrm{COCHCOCH}_{3}\right)_{3} \mathrm{Ir}$ (abbrev. $\left.\mathrm{Ir}(\mathrm{aa})_{3}\right)$ and $\left(\mathrm{CH}_{3} \mathrm{COCHCOCH}_{3}\right)_{3} \mathrm{Pt}$ (abbrev. Pt(aa) $)_{3}$ ), precursors were used. These precursors were kept at temperatures between 150 and $220^{\circ} \mathrm{C}$. Vapor pressures for $\operatorname{Ir}(\mathrm{aa})_{3}$ and $\mathrm{Pt}(\mathrm{aa})_{3}$ at $180^{\circ} \mathrm{C}$, for instance, are about 0.1 and 1 torr, respectively. Their vapors were carried by argon gas $\left(50 \mathrm{~cm}^{3} / \mathrm{min}\right)$. Oxygen gas flow rates were changed from 2 to 10 $\mathrm{cm}^{3} / \mathrm{min}$. A quartz tube nozzle was used to introduce the oxygen gas, and the gases were mixed around the substrates. Quartz glass, some single crystals $((100) \mathrm{MgO},(0001),(11 \overline{2} 0),(01 \overline{1} 2)$ sapphire and (111) Si) and $\mathrm{ZrO}_{2}$ electrolyte $\left(\mathrm{Y}_{2} \mathrm{O}_{3}(8 \mathrm{~mol} . \%)\right.$ stabilized $)$ pellets were used as substrates. Deposition temperatures $\left(\mathrm{T}_{\text {dep }}\right)$ were changed between 400 and $800^{\circ} \mathrm{C}$, and total gas pressures $\left(\mathrm{P}_{\text {tot }}\right)$ were controlled from 2 to 100 torr. The experiments were usually performed for $20 \mathrm{~min}$. The film thickness was measured by a thickness tester (Talystep). The surface texture was examined by SEM. The crystal structure and preferred orientation were studied by XRD. The crystallographic (epitaxial) relationship between films and substrates were analyzed XRD pole figures. The electrical properties of the films deposited on the $\mathrm{ZrO}_{2}$ electrolytes were investigated by A.C. impedance spectroscopy in the frequency range between $50 \mu$ and $20 \mathrm{MHz}$ and by a D.C. polarization technique. The measurements were conducted in air in the temperature range between 200 and $800^{\circ} \mathrm{C}$.

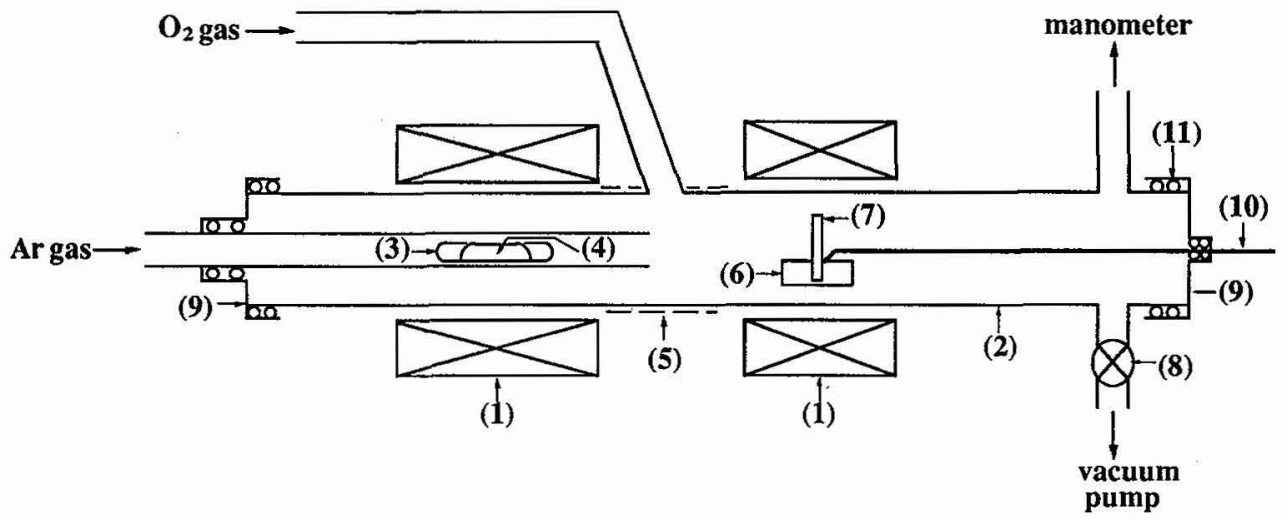

Fig.1 A schematic diagram of horizontal hot-wall type CVD apparatus

(1) furnace, (2) quartz tube, (3) quartz reservoir, (4) precursor powder,

(5) ribbon heater, (6) substrate holder, (7) substrate, (8) needle valve,

(9) flange, (10) thermocouple, (11) o-ring seal

\section{RESULTS AND DISCUSSION}

\subsection{Preparation of films}

Fig. 2 shows the effect of oxygen gas addition on deposition rates for Ir films. Without oxygen addition, the change of activation energy (i.e. from $160 \mathrm{~kJ} / \mathrm{mol}$ to $24 \mathrm{~kJ} / \mathrm{mol}$ ) was observed around $600^{\circ} \mathrm{C}$. This might be correspond to the change of rate-controlling step with increasing temperature from a surface chemical reaction to a gaseous diffusion process [12]. By the addition of oxygen gas, the deposition rates decreased significantly at higher temperatures due to the formation of volatile metal oxide species and/or homogeneous gas phase reactions; the deposition of powdery metals was observed at a low temperature region inside the reaction tube. The Arrhenius plot was linear in the whole 
temperature range; the activation energy was 20 $\mathrm{kJ} / \mathrm{mol}$, which is almost in agreement with that obtained over $600^{\circ} \mathrm{C}$ without oxygen addition.

Fig.3 demonstrates XRD patterns of Ir films prepared on quartz substrates with and without oxygen addition at $T_{\text {dep }}=600^{\circ} \mathrm{C}$ and $P_{\text {tot }}=2$ torr. The XRD peaks for the films prepared without oxygen addition were broader than those with oxygen addition. These broader peaks may imply the smaller grain sizes. Both Ir and Pt films prepared without oxygen addition were black, slightly powdery and poor adherence to the substrates. When a small amount of oxygen gas was added to the source gas, silver-colored films which were strongly adhered to the substrates were obtained. Fig.4 shows the surface and crosssectional texture by SEM observation for the Ir film prepared without oxygen addition. Many small pores were observed on the surface. The oxygen addition seems to cause no remarkable

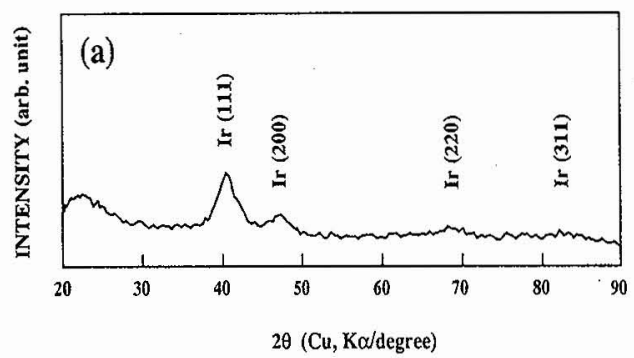

Fig.3 XRD patterns of Ir films prepared on quartz substrates at $\mathrm{T}_{\text {dep }}=600^{\circ} \mathrm{C}, \mathrm{P}_{\mathrm{tot}}=2$ torr (a) without oxygen addition, (b) with oxygen addition $\left(3 \mathrm{~cm}^{3} / \mathrm{min}\right)$

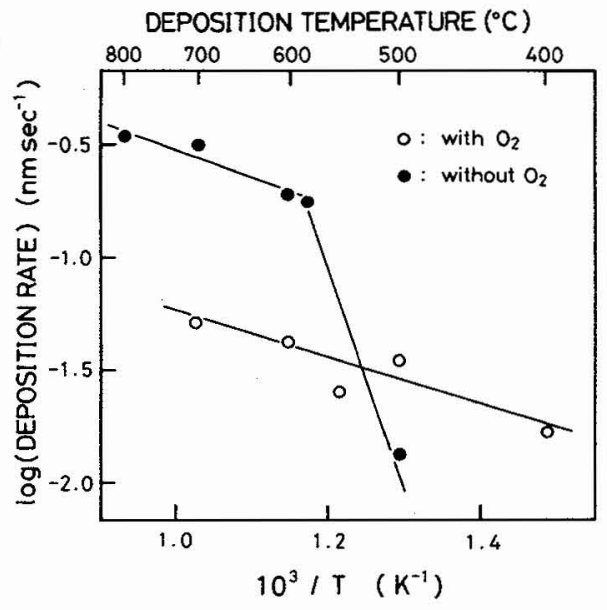

Fig.2 Effect of oxygen gas addition on deposition rates for Ir films

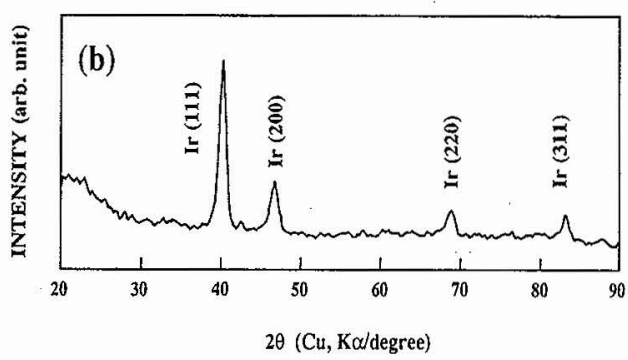

morphology change. The surface texture became more granular and rougher with increasing temperature more than $\mathrm{T}_{\text {dep }}=600^{\circ} \mathrm{C}$.

Fig.5 demonstrates Auger spectra before and after argon sputtering $(2 \mathrm{kV}, 10 \mathrm{~min})$ for Ir films prepared on quartz substrates. Before the argon sputtering, contaminated carbon was observed at the surface for both Ir and Pt films. After the argon sputtering for more than $5 \mathrm{~min}$, contaminated carbon disappeared for the films prepared with oxygen addition. However, strong signals from carbon were identified from the films prepared without oxygen addition even after the argon sputtering, representing a significant amount of impurity carbon. It was estimated that the impurity carbon could be about several at. $\%$.

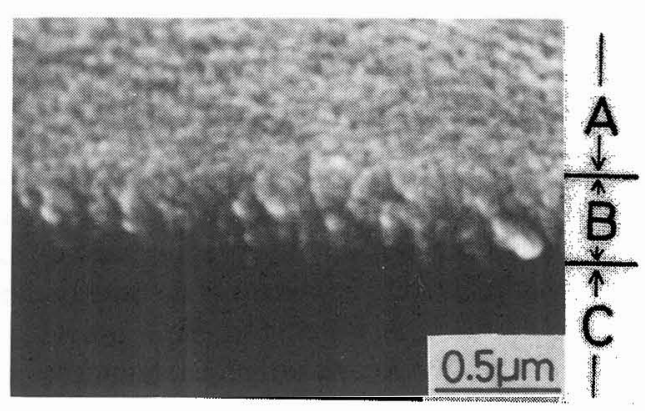

Fig.4 Surface and cross-sectional texture by SEM observation for the Ir film prepared without oxygen addition at $\mathrm{T}_{\text {dep }}=600^{\circ} \mathrm{C}, \mathrm{P}_{\text {tot }}=2$ torr

A: surface, B: cross-section, C: substrate 

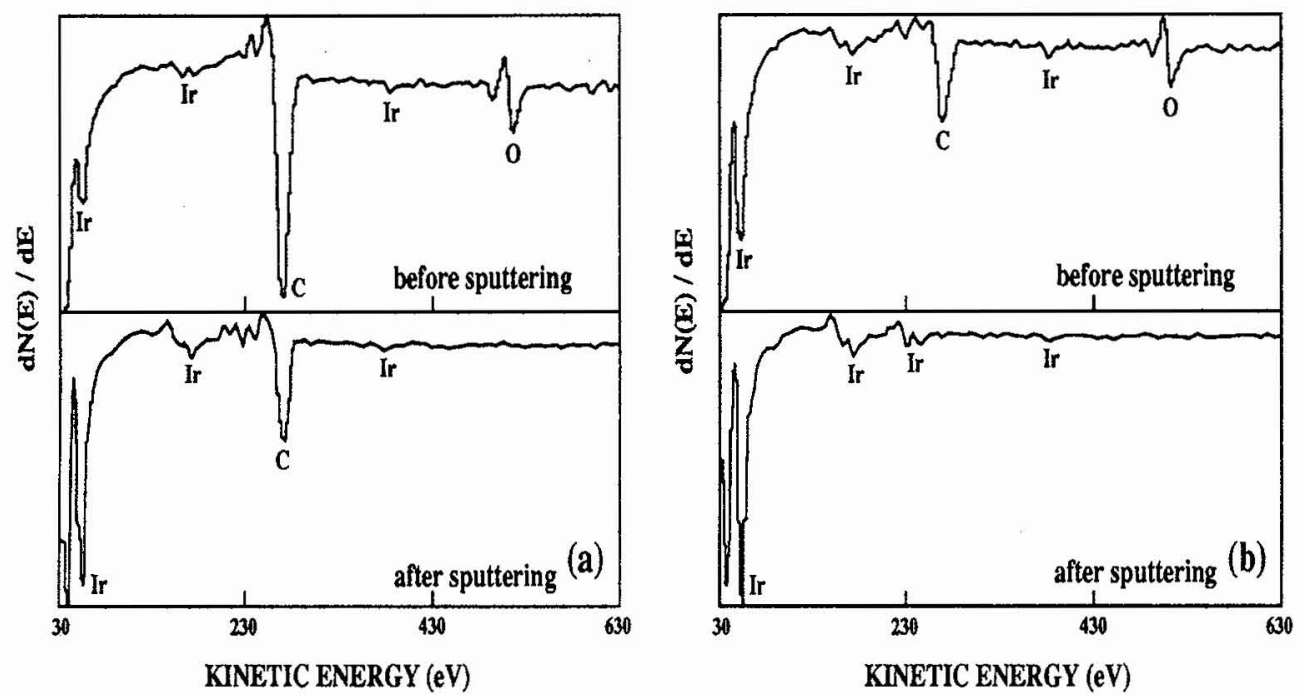

Fig.5 Auger spectra before and after argon sputtering $(2 \mathrm{kV}, 10 \mathrm{~min})$ for Ir films prepared on quartz substrates at $\mathrm{T}_{\text {dep }}=600^{\circ} \mathrm{C}, \mathrm{P}_{\text {tot }}=2$ torr

(a) without oxygen addition, (b) with oxygen addition $\left(3 \mathrm{~cm}^{3} / \mathrm{min}\right)$

Fig. 6 depicts the TEM observation for Ir films prepared without oxygen addition. The Ir deposits are aggregated particles about several nanometers in diameter in spite of their film-like appearance (see Fig.4). This small particle size might be associated with the broader $\mathrm{X}$-ray peaks shown in Fig.3.

The appropriate deposition conditions to obtain highly-pure Ir and Pt films, which is silver-colored (metallic appearance) and smooth surface texture, were as follows; $\mathrm{T}_{\text {source }}=180^{\circ} \mathrm{C}, \mathrm{T}_{\text {dep }}=500$ to $600^{\circ} \mathrm{C}, \mathrm{P}_{\text {tot }}=2$ to 5 torr, $\mathrm{FR}\left(\mathrm{O}_{2}\right)=3 \mathrm{~cm}^{3} / \mathrm{min}$.

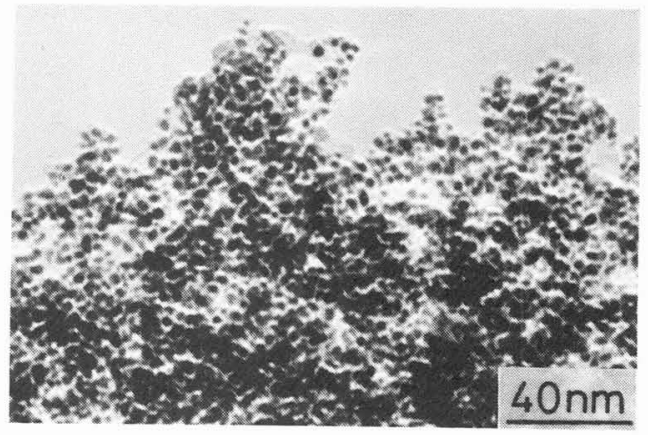

Fig.6 TEM observation for the Ir film prepared on a quartz substrate at $T_{\text {dep }}=600^{\circ} \mathrm{C}$, $P_{\text {tot }}=2$ torr

Fig.7 demonstrates XRD patterns for Ir films on some single crystalline substrates at the abovementioned conditions. Remarkable preferred orientation were observed on $\mathrm{MgO}$ and sapphire substrates depending on the crystallographic planes. No specific orientation was observed for the Si substrates because $\mathrm{SiO}_{2}$ layer was formed on the surface due to oxidation.

Fig. 8 depicts XRD pole figures for Ir films prepared on sapphirc substrates when (100) and (111)Ir planes were dominantly oriented on the $(11 \overline{2} 0)$ and $(01 \overline{1} 2)$ sapphire planes, respectively (see Fig. $7(\mathrm{~b})$ and (c)). In both cases, almost the same poles from substrates were identified. This indicates epitaxial relationship between films and substrates. Table 1 summarizes the epitaxial relationships between films and substrates determined from the pole figure analyses. 


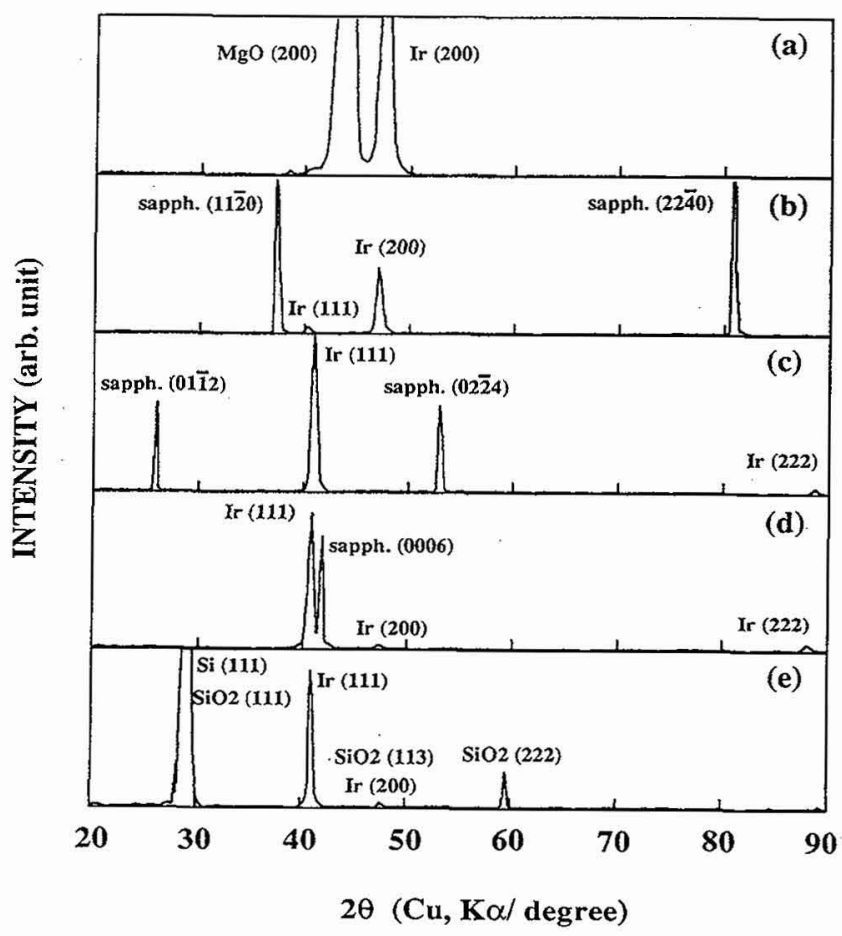

Fig.7 XRD patterns of Ir films prepared at $\mathrm{T}_{\text {dep }}=600^{\circ} \mathrm{C}, \mathrm{P}_{\text {tot }}=2$ torr on single crystalline substrates (a) $\mathrm{MgO}(200)$, (b) sapphire(1120), (c) sapphire(0112), (d) sapphire(0001), (e) $\mathrm{Si}(111)$
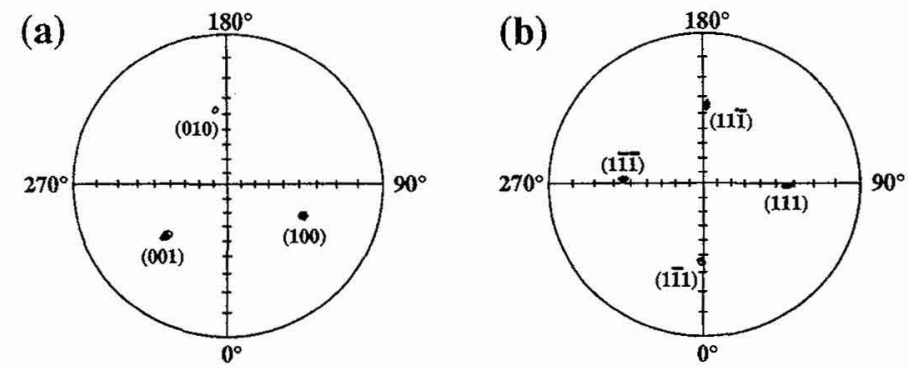

Fig. 8 XRD pole figures for the Ir film prepared on sapphire substrates

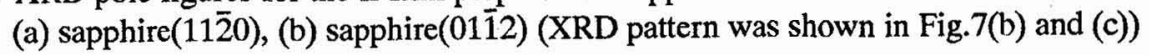

Table 1 Epitaxial relationships of $\mathrm{Ir}$ and $\mathrm{Pt}$ films for $\mathrm{MgO}$ and sapphire substrates

\begin{tabular}{|c|c|}
\hline Substrates & Epitaxial relationship \\
\hline $\mathrm{MgO}(100)$ & $\mathrm{Ir}, \mathrm{Pt}(100) / / \mathrm{MgO}(100) \ldots$ and $\mathrm{Ir}, \mathrm{Pt}[011] / / \mathrm{MgO}[011]$ \\
\hline sapphire $(11 \overline{2} 0)$ & $\operatorname{Ir}, \operatorname{Pt}(100) / /$ sapphire $(11 \overline{2} 0)$ and Ir,Pt[011]//sapphire[11̄00] \\
\hline sapphire(0001) & $\operatorname{Ir}, \operatorname{Pt}(111) / /$ sapphire(0001) and Ir,Pt[211]//sapphire[1]120] \\
\hline sapphire $(01 \overline{1} 2)$ & $\operatorname{Ir}, \operatorname{Pt}(111) / /$ sapphire $(01 \overline{1} 2)$ and $\mathrm{Ir}, \operatorname{Pt}[110] / /$ sapphire[1210] \\
\hline
\end{tabular}




\subsection{Electrical properties}

Fig.9 demonstrates typical A.C. impedance spectra (Cole-Cole plots) in air at $450^{\circ} \mathrm{C}$ for $\mathrm{ZrO}_{2}$ electrolyte pellets in which Ir or Pt films were deposited on both surfaces as electrodes. CVD$\operatorname{Ir}(\mathrm{C})$ and $-\mathrm{Pt}(\mathrm{C})$ mean Ir and $\mathrm{Pt}$ films prepared without oxygen addition containing impurity carbon, and CVD-Ir and -Pt are high-purity Ir and Pt films prepared with oxygen addition (see Fig.5). The A.C. impedance data were analyzed by using three components, i.e. bulk, grain boundary, and some interfacial reaction or diffusion limited process. A semicircle near the original point (at higher frequencies) was assigned to the bulk response due to a small associated capacitance. At lower frequencies (right-hand side in Fig.9), another semicircle which strongly depends on the electrode was observed. This dispersion could be indicative of some interfacial reaction because the circumstance for diffusion process could be almost the same for each electrodes. The grain boundary effect was too small to be resolved in Fig.9 (at $450^{\circ} \mathrm{C}$ ).

The electrode process at the electrode $/ \mathrm{ZrO}_{2}$ interface may be represented by Eq.(1).

$$
2 \mathrm{~V}_{\mathrm{O}}^{\cdot-\cdot}+4 \mathrm{e}+\mathrm{O}_{2}=2 \mathrm{O}_{\mathrm{o}}^{\mathrm{x}}
$$

where $V_{0}^{*}$ is oxygen vacancy, $e$ is electron, $O_{0}{ }^{X}$ is oxygen atom at normal lattice sites. A part of extremely large semicircle (nearly a straight line whose gradient is 45 degree meaning a Warburglike dispersion) can be seen for the CVD-Pt at low frequencies. This implies very difficult interfacial charge transfer; on the contrary, the CVD-Ir(C) has almost no second semicircle which suggests an easy interfacial reaction [13]. The Arrhenius plots for the conductivity associated to the electrode process were shown in Fig.10. The CVD- $\operatorname{Ir}(C)$ has the highest electrode conductivity below $600^{\circ} \mathrm{C}$. There are breaking points in Fig.10 for the CVD-Ir(C) and CVD-Pt(C) films at about 500 and $600^{\circ} \mathrm{C}$, respectively. This may be associated with the oxidation of impurity carbon and/or the morphology change of the fine metal particles due to sintering at higher temperatures. Further study about the thermal stability for those films is underway.

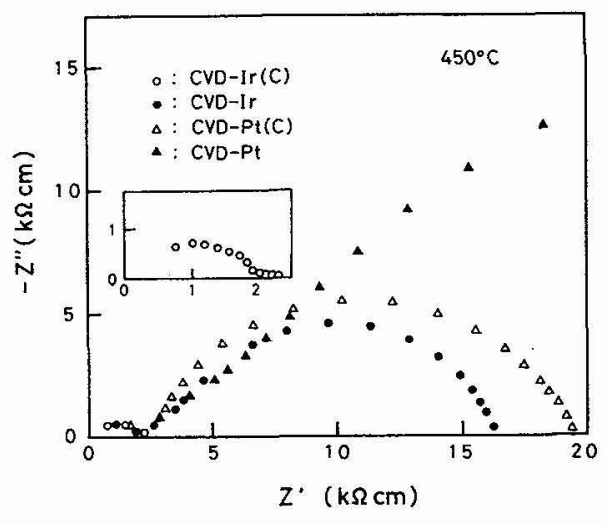

Fig. 9 A.C. impedance spectra in air at $450^{\circ} \mathrm{C}$ for $\mathrm{ZrO}_{2}$ electrolytes using Ir or $\mathrm{Pt}$ films as electrodes

CVD-Ir(C); Ir film, impurity carbon contained CVD-Ir ; high-purity Ir film CVD-Pt(C); Pt film, impurity carbon contained CVD-Pt ; high-purity Pt film

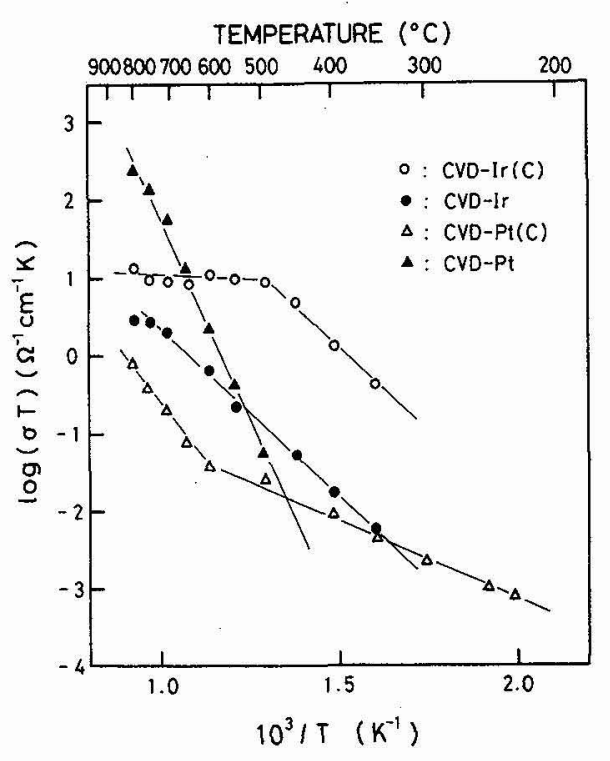

Fig.10 Arrhenius plots for the conductivity associated to the electrode process (in air) 


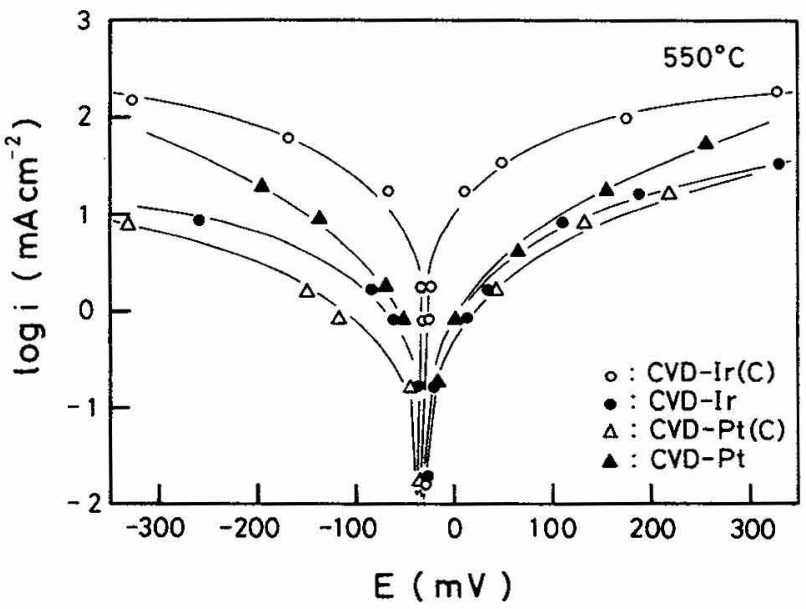

Fig.11 D.C. polarization curves for $\mathrm{ZrO}_{2}$ electrolytes using the $\mathrm{Ir}$ and $\mathrm{Pt}$ films as electrodes (in air at $550^{\circ} \mathrm{C}$ )

Fig.11 shows D.C. polarization curves in air at $550^{\circ} \mathrm{C}$, i.e. the relationship between over-voltage and ionic current passing through the electrolyte [14]. Pure oxygen atmosphere (1 atm) was defined as the standard state. Commercially available Pt electrodes showed almost the same electrical properties (A.C. conductivity and D.C. polarization) as the CVD-Pt films. The CVD- $\operatorname{Ir}(C)$ films passed the highest ionic current under a small over-voltage at $550^{\circ} \mathrm{C}$. This suggests that the electrode process represented by Eq.(1) could be the easiest at the $\mathrm{ZrO}_{2} / \mathrm{CVD}-\operatorname{Ir}(\mathrm{C})$ interface. Therefore, the CVD$\mathrm{Ir}(\mathrm{C})$ films may have the most promising properties as the electrode for $\mathrm{ZrO}_{2}$ electrolyte at a lower temperature range (below $600^{\circ} \mathrm{C}$ ).

\section{CONCLUSION}

Ir and $\mathrm{Pt}$ films were prepared by MOCVD using Ir- and Pt-acetylacetonate as precursors. The appropriate conditions to obtain smooth and uniform films were: $\mathrm{T}_{\text {source }}=180^{\circ} \mathrm{C}, \mathrm{T}_{\mathrm{dep}}=500$ to $600^{\circ} \mathrm{C}$, $\mathrm{P}_{\text {tot }}=2$ to 5 torr. Without addition of oxygen gas, impurity carbon was contained in the films which were black-colored and consisted in aggregated fine particles (several nanometer in size). The Ir films prepared without oxygen addition showed superior electrical and catalytic properties as the electrode for $\mathrm{ZrO}_{2}$ electrolytes. By the addition of a small amount of oxygen gas (about $3 \mathrm{~cm}^{3} / \mathrm{min}$ ) to the source gas, silver-colored, high-purity films were obtained. The deposition rates were significantly decreased by the oxygen addition at high temperatures due to volatile metal oxide formation or homogeneous gas phase reactions. The small amount of oxygen addition to the source gases was effective to obtain epitaxially grown films on single crystalline substrates. The epitaxial relationship was as follows:

$\mathrm{Ir}, \mathrm{Pt}(100) / / \mathrm{MgO}(100) \quad$ and $\mathrm{Ir}, \mathrm{Pt}[011] / / \mathrm{MgO}[011]$

$\mathrm{Ir}, \mathrm{Pt}(100) / /$ sapphire(1120) and $\mathrm{Ir}, \mathrm{Pt}[011] / /$ sapphire[1] 100$]$

Ir,Pt(111)//sapphire(0001) and Ir,Pt[211]//sapphire[11̄20]

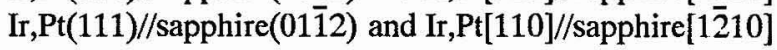




\section{ACKNOWLEDGEMENTS}

This research was supported in part by Grant-in-Aid for New Program from the Ministry of Education, Culture and Science under Contract No.04NP0501. We thank to Japan Storage Battery Co. Ltd. for supporting equipments; also to Mr. H. Masumoto (Tohoku University) and to Dr. Y. Someno (Alps Electric Co. Ltd.) for helping the XRD pole figure and Auger measurements.

\section{REFERENCES}

[1] H. Jehn, J. Less-Common Metals, 100 (1984) 321.

[2] P. Netter, Ph. Campros, Mat. Res. Soc. Symp. Proc., Vol. 168, "Chemical Vapor Deposition of Refractory Metals and Ceramics", Ed. by T. M. Besmann and B. M. Gallois, (1990), Mat. Res. Soc., Pittsburgh, p.247.

[3] D.C. Smith, S.G. Pattillo, N.E. Elliot, T.G. Zocco, C.J. Burns, J.R. Laia and A.P. Sattelberger, in Ref.2, p.369.

[4] V.G. Bessergenev, N.V. Gelfond, I.K. Igumenov, S.Sh. Llyasov, R.D. Kangiev, Yu.A. Kovalvskaya, V.S. Kravchenko, S.A. Slobodyan, V.I. Motorin and A.F. Shestak, Supercond. Sci. Technol., 4 (1991) 273.

[5] H.D. Kaesz, R.S. Williams, R.F. Hicks, Y.A. Chen, Z. Zue, D. Xu, D.K. Shuh and H. Thridandam, Mater. Res. Soc. Symp. Proc., Vol. 131, "Chemical Perspectives of Microelectronic Materials", Ed. by M. E. Gross, J. Jasinski, J.T. Yates, Jr., (1989), Mat. Res. Soc. Pittsburgh, p.395.

[6] E.C. Subbarao, "Science and Technology of Zirconia III, Advance in Ceramics, Vol.24B", Ed. by S. Somiya, N. Yamamoto and H. Yanagida, American Ceramic Society, Westerville, p.731.

[7] T.R. Wright, T.R. Braeckel and D.E. Kizer, Technical report No. AFML-TR-68-6, Air Force Materials Lab., Wright-Patterson, AFB Ohio, 1968.

[8] N. Laegreid and G. K. Wehner, J. Appl. Phys., 32 (1961) 365.

[9] J.M. Criscione, R.A. Mercuri, E.P. Scrom, A.W. Smith and H.F. Volks, Technical report ML-TDR-64-173, 1964.

[10] J. Heiderg, R. Daghighi-Ruhi, H.V. Weyssenhoff, A. Habekost, Mat. Res. Soc. Symp. Proc., Vol. 101, "Laser and Particle-Beam Chemical Processing for Microelectronics", Ed. by D.J.

Ehrlich, G.S. Higashi and M.M. Oprysko, (1988), Mat. Res. Soc., Pittsburgh, p.221.

[11] J.J. Chu, L.J. Chen, K.N. Tu, Mat. Res. Soc. Symp. Proc., Vol. 116, "Heteroepitaxy on Silicon: Fundamentals, Structures and Devices", Ed. by H.K. Choi, H. Ishiwara, R. Hull and R.J. Nemanich, (1988), Mat. Res. Soc., Pittsburgh, p.447.

[12] L.M. Ivanova and A.A. Pletyushkin, Izvest. Akademii Nauk SSSR, Neorg. Mater., 3(1967)1817.

[13] J.R. Macdonald, "Impedance Spectroscopy, Emphasizing Solid State Materials and Systems", John Wiley, New York, (1987), p.191.

[14] J. Mizusaki, H. Tagawa, K.Tsuneyosi and A. Sawata, J. Electrochem. Soc., 138(1991)1867. 